E.L.U.A., 1, 1983, págs. $7-24$

\title{
DE LA LINGÜÍSTICA ORACIONAL A LA SUPRAORACIONAL
}

\author{
Enrique Alcaraz Varó \\ (Universidad de Alicante)
}

\section{LA LINGÜISTICA ORACIONAL}

Tanto para la lingüistica tradicional como para la estructural y la generativa, la oración ha sido la unidad máxima de estudio, análisis y referencia. Recordemos, a estos efectos, la definición clásica de la oración del lingüista medieval alemán Tomás de Erfurt (1): sermo congruus et perfectus; o dicho con otras palabras: suppositum y appositum que expresan un pensamiento completo. Esta última afirmación de "pensamiento completo" es lo que le ha conferido el carácter cerrado de unidad máxima en la lingüística.

También podemos afirmar que, en líneas generales, la lingüística estructural ve en la oración la estructura superior de la que parte para el estudio lingüístico de carácter analítico-taxonómico, distinguiendo en ella, por ejemplo, los componentes inmediatos de la escuela bloomfieldiana, o los funtivos del álgebra lingüística de Hjelmslev formada por determinaciones, interdependencias y constelaciones. Igualmente, la lingüistica generativa, en su desarrollo teórico y práctico, también se sirve de la oración ( 0 ), como unidad máxima, para sus formulaciones arbóreas y lineales $(0 \rightarrow \mathrm{SN}+\mathrm{SV})$.

No obstante, es de justicia reconocer que dos ramas de la lingüís-

(1) ROBINS, R.H. (1968): A Short History of Linguistics, Longman, Londres, págs. 88-9. 
tica, una clásica y otra moderna, han superado ef marco de estudio oracional. Nos estamos refiriendo a la Retórica y a la Estilística.

\section{LA ORACIONALIDAD: GRAMATICALIDAD Y ACEPTABILIDAD}

La lingüistica oracional se basa, en su versión clásica, en cuatro principios, comparables a las cuatro causas aristotélicas (2):

material: las palabras

formal: la unión de las mismas en construcciones (modi significandi)

eficiente: las relaciones expresadas en las formas declinadas.

final: la expresión de un pensamiento completo.

Estas son las condiciones de "oracionalidad"; es decir, las que deben concurrir en un conjunto de palabras para que se le pueda llamar oración. Estos principios se pueden resumir en los dos de la definición de oración de Tomás de Erfurt, es decir, que el conjunto de palabras sea congruus y perfectus.

En la lingüística moderna se ha tomado como valor entendido, que la oración debe basarse en dos principios que expuso N. Chomsky en forma dicotómica: gramaticalidad y aceptabilidad. Entendemos por gramaticalidad de una oración la adecuación de su forma externa a los principios o reglas del sistema (competencia lingüística) de los participantes (emisor y receptor) en la comunicación. En las oraciones de Chomsky (3)

John found sad.

John elapsed that Bill will come.

John became Bill to leave.

hay agramaticalidad porque las construcciones sintácticas no se adecúan a las reglas de categorización de la naturaleza de los verbos find, elapse y become.

También encontramos agramaticalidad en estas oraciones:

La Junta de Gobierno está obligado a ello.

Todo el mundo se pusieron a gritar.

Te prometo que lo hice.

La gramaticalidad confiere a la oración su unidad externa, y ésta se logra cuando se cumplen las reglas morfológicas (uso correcto de los

(2) Ibid., pág. 88.

(3) CHOMSKY, N. (1965): Aspects of the Theory of Syntax, The MIT Press, Cambridge (Mass.), pág. 148. 
morfemas de género, número, tiempo, aspecto, persona, etc.), y las sintácticas (categorización apropiada de las construcciones sintácticas; por ejemplo, hay verbos que requieren sujetos que posean el clasema [+animado] o el [-animado], los verbos transitivos no pueden tener a un adjetivo como complemento directo: John found sad, etc.). Estas dos características de la gramaticalidad corresponderían a los principios formal y eficiente de la lingüística medieval citada más arriba.

También le confiere gramaticalidad a la oración, la entonación correspondiente y la pauta rítmica apropiada (esta última muy especialmente en lenguas como el inglés en las que representan un papel muy relevante las vocales largas y breves, y las tónicas y las átonas). En la oración aseverativa

Cuando vengas, te lo contaré

no hay gramaticalidad si queremos afirmar algo, porque las curvas de entonación están cambiadas. Las curvas más probables en una afirmación serian:

\section{Cuando vengas, ste lo contaré.}

Al hablar de entonación, incluimos también otros rasgos prosódicos como la pausa o la juntura. Es muy conocida la frase $u$ oración «La Alianza para el progreso" con sus dos interpretaciones (para forma del verbo parar, o preposición que expresa finalidad) debidas al haz de rasgos prosódicos que actúen.

Decimos que una oración posee aceptabilidad, es decir, es congruus en la terminología de Tomás de Erfurt, cuando mantiene una estabilidad cognoscitiva el pensamiento expresado en ella con el conocimiento que los participantes en la comunicación poseen sobre el mundo llamado real o contextual en que es emitida, el cual puede pertenecer a la ficción, a la ciencia o a la fantasía. De esta forma, las siguientes oraciones son aceptables:

El átomo es mortal.

Son átomos para la paz.

El átomo no es indivisible, etc.

Es clásico ya, el ejemplo dado por N. Chomsky de inaceptabilidad en una oración: "Las verdes ideas incoloras duermen furiosamente". En una interpretación producida por descodificación automática, no es congruente que algo pueda ser «verde" e «incoloro" a la vez, e igualmente es inaceptable que la predicación simultánea de "verde" e «incoIoro" se pueda aplicar a un objeto no material, como son las ideas. 


\section{LA INTERPRETACION DE LA ORACION}

La interpretación de una oración gramatical se lleva a cabo por medio de lo que llamamos descodificación automática, en la que entran en acción los sememas y clasemas de las unidades léxicas simpies, compuestas y complejas y las funciones de las construcciones sintácticas que el lector/receptor activa de acuerdo con su conocimiento del mundo o realidad. Por ejemplo, la oración

\section{Un alpinista intrépido ascendió al pico del monte}

es gramatical porque se cumplen las reglas de la gramaticalidad citadas antes, entre las que destacamos las reglas de concordancia y de régimen, que están adecuadamente aplicadas: alpinista, aún acabando en $-a$, puede ser masculino, al igual que un e intrépido; ascender rige la preposición a, etc.

Desde el punto de vista de la aceptabilidad, es perfecto: la cualidad “intrépido" se puede predicar de los «alpinistas», y «ascender» está entre las acciones esperadas en el «pico del monte».

En cambio, la oración

Un fantasma corpóreo ascendió al fondo del mar

tiene gramaticalidad, ya que aunque fantasma acaba en -a puede ser masculino, y concuerda con un y corpóreo, y el régimen verbal es correcto, pero la aceptabilidad no se produce por descodificación automática. En el sintagma «un fantasma corpóreo" hay un choque clasemático o de reglas de selección entre "fantasma» y «corpóreo», e igualmente hay un choque entre «ascender»y «fondo del mar.»

Sin embargo, es sorprendente e incluso misteriosa la capacidad humana para interpretar y desambiguar los sentidos de una oración y asignar valores denotativos y connotativos a las distintas unidades de significación. Con la oración anterior, o con otras similares, caben dos opciones: desecharla por absurda, o darle una interpretación por medio de descodificación no automática. En este segundo caso, podemos hallarnos ante un lenguaje técnico o ante un lenguaje figurado. Si el lenguaje es técnico, la interpretación se resuelve acudiendo a un glosario o vocabulario apropiado; si el lenguaje es figurado, nos encontramos ante la función poética del lenguaje de Jakobson. Para interpretar el lenguaje figurado tenemos que hacer hipótesis pragmáticas, es decir, elecciones que nos permitan superar las incompatibilidades citadas, pasando de esta manera al campo de las metáforas y connotaciones, $o$ 
"recrear" otros mundos o contextos que nos faciliten una interpretación.

Una primera elección, para llegar a la interpretación, podría consistir en considerar, que hay personas (cuerpos) que se comportan fantasmagóricamente, es decir, están y no están, son escurridizos, no se comprometen a nada, etc.

En la elección anterior hemos dado sustantividad a «corpóreo»; en una segunda interpretación, en el mundo textual de la fantasía, podemos pensar que los fantasmas que viven en un mundo "noetós» toman forma corpórea al viajar al mundo "aescetós». E igualmente se podría salvar "ascender al fondo del mar", si el lugar residencial de los fantasmas, que nos facilita el contexto, es el centro de la tierra, etc.

La oración chomskiana "Verdes ideas incoloras..." sería aceptable si tomamos "verde" en su sentido de «inmaduro", e «incoloro" en el de "soso, insulso". Asi se trataría de ideas que no han sido maduradas y además no tienen atractivo por ser insulsas, etc.

\section{LA LINGÜÍSTICA TEXTUAL}

La meta de la lingüística supraoracional es superar o ir más allá de la oración, considerada como unidad máxima de sentido y como meta de análisis.

El interés de la lingüistica por superar el marco de la oración viene determinado por el auge de otras disciplinas relacionadas con la comunicación: la semiótica y la pragmática. Entre la lingüística, la semiótica y la pragmática existen relaciones estrechas. La semiótica es la ciencia que estudia los signos comunicativos (música, artes plásticas, cine, etc.). La lingüística es una parte de la semiótica, pero el área de acción de la lingüística son los signos lingüísticos, es decir, los que tienen doble articulación, o sea, monemas (unidades significativas) y fonemas (unidades distintivas), y la pragmática es una parte de la linguǐstica. Si ésta es la ciencia de los signos linguísticos, éstos pueden ser estudiados con relación al mundo (la semántica), con relación a otros signos (la sintaxis), y con relación a los que los usan (la pragmática) (4):

Los objetivos de la semiótica y la pragmática van más allá de la oración, al abordar cuestiones tales como la comunicación, y han influido en la lingüística para que ésta amplie el marco de referencia por encima de la oración. Esta lingüística supraoracional aborda simultá-

(4) MORRIS, CH. (1962): Signos, Lenguaje y Conducta, Losada, Buenos Aires. 


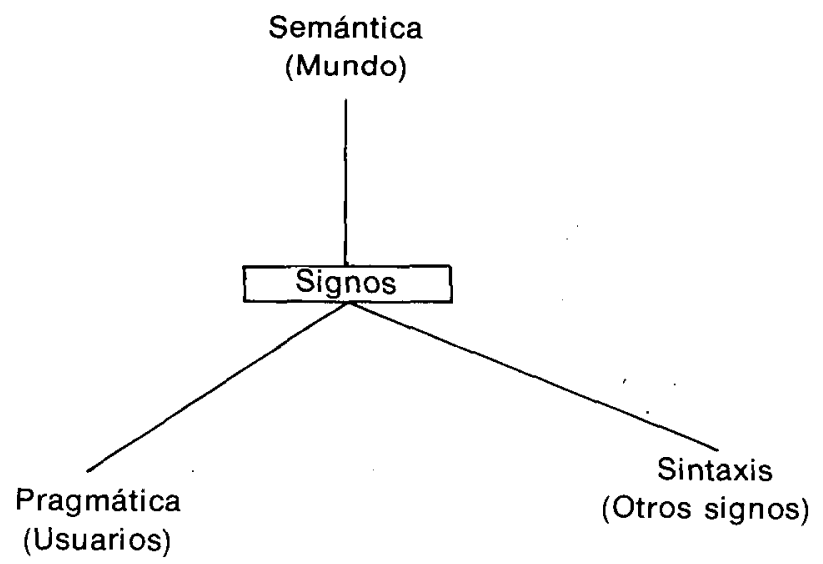

neamente las tres ramas antes citadas: la sintaxis, es decir, el signo lingüístico relacionado con otros signos lingüísticos, la semántica, o sea, el signo lingüístico con el mundo al que se refiere, y la pragmática, o sea, el uso, la elección y decisión que adoptan sobre el signo las personas que intervienen en la comunicación.

A la lingüistica supraoracional también se la llama lingüistica del texto o textual, y su objetivo es "descubrir y sistematizar las estrategias que permiten la utilización de los textos" (5) que, como puede deducirse, es muy ambicioso, puesto que implica el estudio simultáneo de la sintaxis, de la semántica y de la pragmática en los términos apuntados por Charles Morris.

La palabra "texto" es un término de difícil definición, y algo difuso por su amplia extensión o aplicabilidad. Hjelmslev lo utilizó asignándole el significado de "proceso», similar al de habla o discurso, y dicotómico con el de sistema (6). Provisionalmente diremos que el texto es una unidad de sentido cerrada, formada al menos por una oración, que posee textualidad, y que se manifiesta en forma de discurso. Pero como afirman T. Albaladejo y A. G. ${ }^{a}$ Berrio (7) «es de gran interés todavía para el lingüista textual la delimitación de la unidad lingüística texto, y éste

(5) BEAUGRANDE, R. y DRESSLER, WOLFGANG (1981): introduction to Text Linguistics, Longman, Londres, pág. 35.

(6) HJELMSLEV, L. (1961): Prolegomena to a Theory of Language, The University of Wisconsin Press, págs. 37 y 39.

(7) ALBALADEJO, T. y GARCIA BERRIO, A. (1983): "La lingüística del texto", págs. 217263 en Varios, Introducción a la Lingüistica, Alhambra, Madrid. 
es un capitulo de la investigación que de ningún modo puede considerarse cerrado.»

\section{LA TEXTUALIDAD: COHESION Y COHERENCIA}

En el punto 2 vimos los principios que confieren la "oracionalidad" a un conjunto de palabras. Al texto le ocurre lo mismo que a la oración, y entre los principios que otorgan a un conjunto de oraciones la textualidad, es decir, la calidad de texto, destacamos dos: cohesión y coherencia.

Estos dos términos que son clave en la lingüística textual (8) guardan, en nuestra opinión, una estrecha relación con los de gramaticalidad y aceptabilidad de una oración. La unidad interna que a la oración le da la aceptabilidad es conseguida en el texto por la coherencia, y la unidad externa de la oración lograda por la gramaticalidad es alcanzada en el texto por la cohesión.

Son elementos de la cohesión textual, en primer lugar, los que producen la gramaticalidad de la oración: la entonación, el ritmo y demás rasgos prosódicos como la pausa y la juntura; la concordancia (morfemas de género, número, etc.); el régimen apropiado; la correcta categorización de las construcciones sintácticas, etc., como hemos señalado más arriba. Además de los elementos que intervienen en la gramaticalidad, hay otros que son típicos exclusivos de la cohesión, entre los que destacamos dos fuerzas que actúan en sentido opuesto: la anáfora y la catáfora. La anáfora va hacia atrás, hacia lo ya mencionado; la catáfora se mueve hacia adelante. La que mira hacia lo nombrado, la anáfora, se sirve de elementos sustitutivos que repiten las unidades nombradas; la otra, la catáfora, anticipa en los elementos empleados rasgos o caracteristicas de las unidades que se descubrirán más adelante. Los elementos usados en la catáfora "generan incertidumbre y por tanto intensifican el interés del receptor" (9); en cierto modo, la catáfora suscita una expectativa y "ayuda a proyectar al lector hacia la historia." (10).

Entre los elementos que se emplean en la anáfora destacan los pronombres:

Trajo una caja. La puso en la mesa y de ella sacó un objeto extraño...

(8) HALLIDAY, M. y HASAN, R. (1976): Cohesion in English, Longman, Londres. BEAUGRANDE, R. Y DRESSLER, W.: op. cit.

(9) BEAUGRANDE, R. y DRESSLER W. op. cit., pág. 61.

(10) Ibid. 
Mrs. Long is a sincere person. She has been in this school for over ten years; those who know her...

That's a funny car. I never saw one like that.

Los ingleses y los españoles tienen temperamentos distintos. Estos son apasionados, aquéllos flemáticos.

Dentro de los pronombres, destaca por su permanente carácter anafórico, el relativo:

Pasamos el día cerca de un puente de piedra, el cual fue construido con toda probabilidad hacia el siglo xII.

Los determinantes, entre los que destaca por su frecuencia en el texto el artículo determinado, también pueden poseer la fuerza anafórica que otorga la cohesión al texto:

Pasamos el día cerca de un río. E/ río llevaba un agua pura y cristalina.

Unemployment is the question that worries most people in Europe. Another issue is inflation.

Love and war are universal terms; such words exist in all sorts of cultures.

Especial fuerza anafórica poseen las conjunciones coordinantes copulativas, disyuntivas y adversativas, y las subordinantes temporales, concesivas, causales, consecutivas, etc.

También el adverbio posee fuerza anafórica. Quirk y Greenbaum (11), clasifican los adverbios en tres grupos: los adjuntos, los disjuntos y los conjuntos. Los conjuntos, equivalentes a lo que tradicionalmente llamamos adverbios o locuciones conjuntivas, tiene capacidad de enlace, y a estos efectos, es muy interesante la subclasificación que facilita:

enumerative: to begin with, to conclude, last, finally, etc.

reinforcing: in addition, what is more, above, all, etc.

equative: in the same way, likewise, etc.

transitional: by the way, incidentally, etc.

summative: to sum up, in conclusion, in all, etc.

apposition: for example, namely, that is to say, etc.

result: as a result, hence, therefore, etc.

inferential: in other words, in that case, etc.

(11) QUIRK, R. y GREENBAUM, S. (1973): A University Grammar of English, Longman, Londres, págs. 207-250. Para un estudio profundo de los nexos en español véase E. Ramón Trives (1982): La dinámica oracional, Ed. Godoy, Murcia. 
replacive: on the other hand, rather, alternatively, etc. antithetic: in contrast, on the contrary, etc.

concessive: after all, all the same, besides, etc.

Pero nosotros pensamos que también pueden poseer fuerza anafórica los adjuntos, los cuales se diferencian de los conjuntos y los disjuntos por estar plenamente integrados en la estructura oracional:

Paramos en una posada. Alli encontramos lumbre y comida durante algunos días.

E igualmente poseen fuerza anafórica los disjuntos, que son adverbios que informan del comentario que el que habla tiene sobre lo que dice, ya el fondo ya la forma:

Todos deben participar en la función teatral. Obviamente, quedan disculpados los que se encuentren en el viaje de fin de curso en ese momento.

Catafóricamente pueden actuar los pronombres:

Estos son los grandes pecados del mundo occidental en el que vivimos: egoismo e hipocresia.

Ours is a party where everybody makes friends easily.

También pueden actuar catafóricamente prácticamente la mayoría de los adverbios y conjunciones citados:

Aunque dedicó casi todo su tiempo a preparar las oposiciones, falló en el momento de la verdad.

Igualmente actúan catafóricamente los gerundios, los participios y los adjetivos en las construcciones llamadas absolutas:

Buscando un traje en las rebajas, compramos este abrigo para el abuelo.

Anxious for a quick decision, she rang up her boss at $1 \mathrm{am}$.

Abatidos por el calor y la sed, sucumbieron los aguerridos soldados.

Se dice que un texto posee coherencia cuando hay continuidad de sentidos o ausencia de contradicción cognoscitiva entre el conocimiento activado por las expresiones del texto y el conocimiento del mundo de los participantes en la comunicación. Este conocimiento está constituido por una configuración de conceptos y relaciones (12). A esta configuración de conceptos y relaciones se le suele llamar el "mundo real", pero cuando los conceptos y las relaciones se configuran en el texto tenemos el "mundo textual». En un sentido amplio,

(12) BEAUgRANDE, R. y DRESSLER, W.: op. cit., pág. 84. 
todos los mundos son textuales, ya que las relaciones nacidas en el texto influyen para la coherencia entre el contenido del texto y el mundo cognoscitivo mencionado arriba. Pero el mundo real o cultural es previo y definitivo. El texto:

He lidiado problemas más graves; casi siempre en el ruedo, a veces desde el callejón, pero desafortunadamente para mí nunca desde la barrera.

tiene coherencia (“continuidad de sentidos») porque los problemas que se plantean están comparados dentro del mundo real de los hispanohablantes. Si el mundo textual se hubiera construido sirviéndose de la configuración de conceptos y relaciones existentes en el golf, el cricket, el badmington o el squash la continuidad de sentidos habría sido inexistente o mínima.

Un caso típico de configuración de conceptos y relaciones textuales es el que nace, por ejemplo, en la lectura de «Alicia en el país de las maravillas». No obstante, cualquier marco, ideológico o político, cultural o científico crea un mundo de conceptos y relaciones.

Un recurso que es definitivo para la estabilidad de sentidos que constituye la coherencia, y en su caso, para la formación del mundo textual, es la repetición de componentes conceptuales en el discurso del texto. Como dice van Dijk «los componentes conceptuales se repiten para mantener la coherencia textual» (13). Esta repetición de componentes conceptuales, conocidos con el nombre de semas en la lingüística estructural, se llama isotopia, la cual ha sido definida por Greimas (14) como "haz de categorías semánticas redundantes subyacentes al discurso considerado».

En las isotopías, los semas que se repiten pueden estar lexicalizados o formando parte de los sememas de otras lexías o unidades léxicas. Las principales relaciones que mantienen los semas entre sí son las siguientes: sinonimia, antonimia, implicación, conversión, hiperonimia e hiponimia (15). He aquí el campo semántico formado por las relaciones citadas en torno a la tendencia isotópica agression. El estudio se ha hecho sobre los capítulos 1 y 8 de la novela de John Wain

(13) VAN DIJK, T.A. (1969): "Semantique structural et analyse semantique» págs. 28-54, Lingua, 23, pág. 54.

(14) GREIMAS, A.J. (1966): Semantique Structural. Recherche de Méthode, Larousse, París.

(15) ALCARAZ, E. (1982): Semántica de la Novela Inglesa. Publicaciones de la Caja de Ahorros Provincial de Alicante, págs. 101-124. 
Hurry On Down. La primera cifra se refiere a la página, y la segunda a la línea de dicha página (16).

a) El sema agression y algunos sinónimos:

AGRESSION: attack that has no cause or reason.

19.31 that was thrust aggressively into his

OFFENSIVELY: attacking

16.1 a punishable offence

17.4 Edith, who began the offensive

(Esta palabra tiene doble connotación, la de acción militar, aunque se emplee también en deportes, y la de delito).

ABUSE: attack with words.

27.26 the hailstorm of abuse

Son sinónimos de abuse, las lexías insult y to beset:

INSULT: attack with words; it connotes "hurting people's feelings".

14.7 as a simple insult

TO BESET: to attack; it connotes "to surround, to corner somebody".

14.14 all the problems that beset him

BARRAGE: attack with rapid delivery of speech; it connotes "artillery".

23.37 a barrage of meaning glances

Offence es un sema descriptivo de to accuse, menace, suspicion y to defeat, con los que está relacionados:

TO ACCUSE: to charge with offence.

7.12 her beady, accusing eyes

9.15 who was accused

MENACE: to show the intention to attack.

19.16 heavy with menace

21.38 he said menacingly

27.27 the menacing approach of the landlord

TO DEFEAT: to win a victory over by attacking.

11.34 a sense of defeat

(Son sinónimos parciales de to defeat las lexías to overpower y to devastate; la primera connota "fuerza", y la segunda "violencia»).

TO OVERPOWER: to defeat by force.

18.29 unless one overpowered them

TO DEVASTATE: to defeat with destruction.

18.23 a quick devastating reply

(To win también es sinónimo parcial, pero su connotación es la de "competición o concurso").

(16) Ibídem, págs. 206-210. 


\subsection{7 his point was won}

(Suspicion también está relacionado con offence y aggression).

SUSPICION: Intuitive realisation of offence or aggression.

8.4 her reedy voice full of suspicion

8.19 her suspicions were violently aroused

9.26 the suspected man

10.8 half-suspicious

Agression también está relacionado con weapon y sting, como implicación de instrumento.

WEAPON: something designed for fighting, attacking, etc.

17.20 a weapon against him.

STING: sharp pointed organ that insects use to attack or defend themselves.

25.23 deprived of his sting.

b) El converso de "agredir" es «defender" o "proteger»:

TO PROTECT: keep safe against attack

27.24 (it) protected him

27.38 to protect him

DEFENCE: thing used for protecting or defending.

18.8 ripped down his defences

(Defence es un sinónimo parcial de to protect; to expose oneself es el antónimo de to protect).

TO EXPOSE ONESELF: to deprive of protection.

15.26 he was exposing himself

c) Los verbos que siguen están relacionados con el sema central porque todos poseen la connotación de "aggresion".

TO BEAT: to hit repeatedly and cruelly

20.18 his own footsteps beat into his head.

TO KICK: to hit with the foot

10.4 the kick he would plant

29.9 kicking savagely at a football

TO RAP: to hit slightly

24.40 and rapped it on the counter

TO-FLICK: to give a light blow

21.3 (it) flicked his mind empty

TO BANG: to strike with a sharp noise

14.27 banging down cards.

Y por último, la palabra aggression está relacionada con violence como hipónimo de ésta. 
En el segundo capítulo desciende el índice de presencia a $4.24 \%$. Abundan las lexías de defensa y de seguridad, aunque aparece la lexía que significa "agresión repetida, organizada y regulada", es decir, "la guerra".

WAR: organised aggression repetitive and regulated.

170.5 the sporadic warfare beetween athletes and aesthetes

171.24 the war of the...

STRUGGLE: fight, war, it connotes "efforts and force".

169.8 that struggle

CLASH: struggle; it suggests physical contact which may be sudden.

171.22 several open clashes Burge.

Casi todas las lexias que siguen ya han aparecido en el primer capítulo:

PROTECTION

169.6 his protective colouring

181.6 economic and emotional protection

DEFENCE

196.19 she cut across his defence

TO STAND UP TO / FOR

172.22 hospital orderly standing to the...

196.36 a woman standing for another woman

TO FEND OFF: to defend oneself from.

192.28 he must fend off

APOLOGY: defence

196.20 accusation and apology

196.21 lame apology

SAFE: in protection

169.7 that jungle in safety

190.34 he would be safe and hidden 


\section{EL CAMPO EN TORNO A «AGGRESSION"}

To stand up for

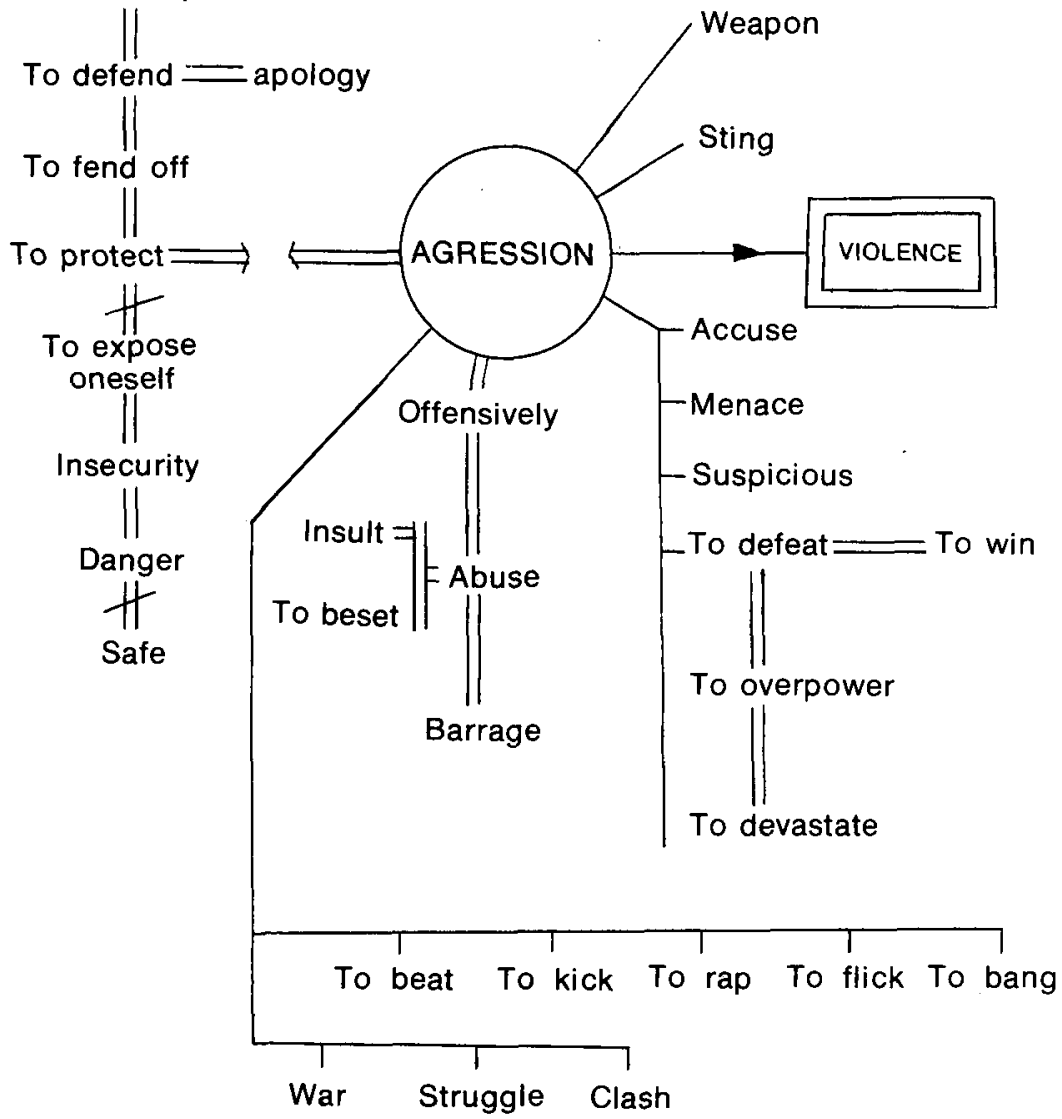

Como vemos, la repetición es la base fundamental sobre la que se apoya la conerencia textual, al igual que lo es en la anáfora y en la catáfora en su contribución a la cohesión, junto con los elementos de la gramaticalidad de la oración. En realidad, la cohesión y la coherencia tienen mucho de común; en aquélla, la repetición apunta hacia la uni- 
dad textual por medio de enlaces y de vínculos, y en ésta forma la estabilidad cognoscitiva. Esta semejanza hace que algunos tratadistas sólo hablen de coherencia, y a lo sumo, distinguen una coherencia externa y otra interna. Es el mismo problema que se plantea al querer ver en la oración el significante por una parte, y el significado por otra, o al reducirlo todo a semántica, ya que todo porta significado: la elección de los alófonos, la entonación, el orden sintáctico, etc. Nosotros creemos que es útil esta distinción entre cohesión y coherencia apuntada por varios lingüistas. Aunque las dos se apoyan en la repetición, poseen características distintivas: la cohesión usa elementos sustitutivos que, en principio, no tienen toda la carga semántica (aunque sí la correferencia) y poseen más valor de enlace, mientras que la coherencia se sirve de la repetición para el establecimiento de la estabilidad cognoscitiva. No obstante, no se debe olvidar que la cohesión se apoya en la coherencia, y ésta difícilmente tiene sentido sin aquélla.

\section{LA DESCODIFICACION TEXTUAL}

Al hablar de la interpretación de la oración deciamos que en la descodificación automática había elección de sememas de las lexías por parte del lector/receptor. En la interpretación de un texto, en el que el lector-receptor tiene que acumular gran cantidad de información, para establecer la línea de estabilidad cognoscitiva debe llevar a cabo un proceso pragmático llamado tematización, mediante el cual, un sema por su repetida presencia en el texto es elevado automáticamente a la categoría de tema, que es marco de referencia para una descodificación automática.

Al leer el siguiente texto

El banco estaba muy lleno. Los pescadores rebosaban de alegría. Habían llegado ya los buenos tiempos.

el lector no ha hecho aún la tematización o elección definitiva del tema isotópico, debido a que en este caso la lexía "banco" tiene, por lo menos, dos sememas atribuibles.

Al seguir leyendo, si se encuentra con esta oración

Las redes apenas soportaban el peso de los peces

establece la isotopía tematizada PEZ, ya que "pescador", "red" y "banco" poseen el sema "pez». En cambio, si el texto hubiera seguido de esta manera 
El cajero dio a cada uno medio millón por el buen trabajo de la temporada

la línea temática habría sido diferente. Cuando esta tematización no la ha realizado el lector después de recibir información contenida en un texto de varias oraciones, debe volver al principio, si se trata de una lectura, o requerir del interlocutor la información precisa para la tematización, que será cauce por donde discurra la estabilidad cognoscitiva.

\section{ClASES DE TEXTOS}

El texto puede ir desde una oración a una obra literaria. Textos intermedios pueden ser los capítulos y los párrafos. El párrafo es el texto formado por un trozo de discurso que, en la escritura comienza con una letra mayúscula (pausa absoluta en la emisión oral) y termina con un punto y aparte. El párrafo bien construido es un texto que posee un alto índice de cohesión y de coherencia que le permite la existencia independiente. Pero la forma más privilegiada de texto breve es la estrofa. En ella la cohesión y la coherencia son perfectas. En el soneto la coherencia queda bien atada porque normalmente el último terceto condensa el contenido de las formas anteriores, como se puede observar en Soneto XXIII de Garcilaso de la Vega

En tanto que de rosa y de azucena se muestra la color en vuestro gesto, y que vuestro mirar ardiente, honesto con clara luz la tempestad serena;

$y$ en tanto que el cabello, que en la vena del oso se escogió, con vuelo presto por el hermoso cuello blanco, enhiesto, el viento mueve, esparce y desordena:

coged de vuestra alegre primavera el dulce fruto antes que el tiempo airado cubra de nieve la hermosa cumbre.

Marchitará la rosa el viento helado, todo lo mudará la edad ligera por no hacer mudanza en su costumbre. 
Igualmente, la estrofa spenceriana participa de los rasgos anteriores:

\section{Amoretti: 15}

Ye tradeful Merchants, that with weary toil, Do seek most precious things to make your gain; And both the Indias of their treasure spoil, What needeth you to seek so far in vain?

For lo my love doth in her self contain All this world's riches that may be far be found, If Saphhires, 10 her eyes be saphhires plain, If Rubies, lo her lips be rubies sound:

If pearls, her teeth be pearls both pure and round; If Ivory, her forehead ivory ween;

If Gold, her locks are finest gold on ground; If silver, her fair hands are silver sheen.

But that which fairest is, but few behold, Her mind adornd with virtues manifold.

En este caso, es el pareado final el que fuerza la coherencia del texto, resumiendo la línea significativa de la estrofa.

La rima y el ritmo son elementos de cohesión, conforme hemos dicho más arriba; sin embargo, en parte de la poesía moderna, especialmente la de lenguas como el inglés en las que el juego entre vocales largas/breves y tónicas/átonas tiene mayor relevancia que en otras, el ritmo se convierte en elemento de coherencia, como ha apuntado $D$. Attridge (17): "some modern poetry uses rhythm cohesion as the major unifier of semantically unrelated or conflicting elements» (el subrayado mio).

\section{CONCLUSIONES}

A modo de resumen, sistematizamos los puntos más importantes abordados en este trabajo:

(17) ATTRIDGE, DEREK (1982): The Rhythms of English Poetry, Longman, Londres, pág. 307. 
(1) Existe, en nuestra opinión, un cierto paralelismo entre las dicotomías "gramaticalidad/aceptabilidad", base de la oracionalidad, y "cohesión y coherencia", fundamento de la textualidad.

(2) La repetición es necesaria para la formación de la cohesión y la coherencia textual. Para la coherencia son imprescindibles las repeticiones isotópicas: por una parte, facilitan al lector/receptor la elección pragmática llamada "tematización" (conocida también con el nombre de "topicalización"), y por otra, colaboran en el mantenimiento de la estabilidad cognoscitiva del texto.

(3) Como consecuencia de lo anterior, afirmamos que la repetición, que ha sido objeto de estudio en la Retórica (la aliteración, el paralelismo, la correlación, etc.), puede ser reveladora en la lingüística textual, por sus funciones y efectos; igualmente, puede ser motivadora, por su carácter insinuador y sugestivo, la elipsis textual, que junto con la repetición forma una dicotomía de trabajo. 